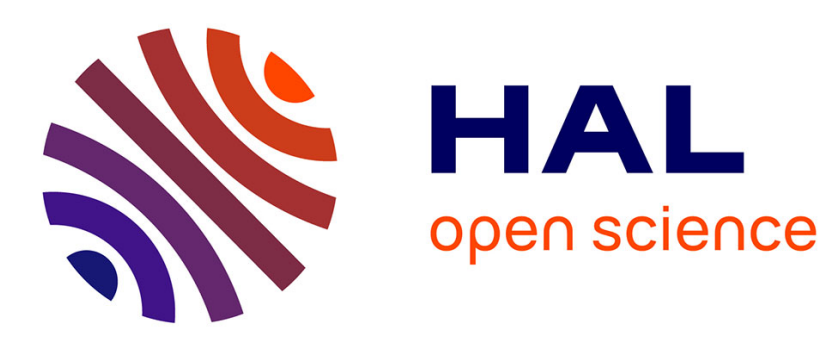

\title{
Synergies and complementarities of CloudSat-CALIPSO snow observations
}

\author{
Alessandro Battaglia, Julien Delanoë
}

\section{To cite this version:}

Alessandro Battaglia, Julien Delanoë. Synergies and complementarities of CloudSat-CALIPSO snow observations. Journal of Geophysical Research: Atmospheres, 2013, 118 (2), pp.721-731. 10.1029/2012JD018092 . hal-00777024

\section{HAL Id: hal-00777024 \\ https://hal.science/hal-00777024}

Submitted on 31 Aug 2020

HAL is a multi-disciplinary open access archive for the deposit and dissemination of scientific research documents, whether they are published or not. The documents may come from teaching and research institutions in France or abroad, or from public or private research centers.
L'archive ouverte pluridisciplinaire HAL, est destinée au dépôt et à la diffusion de documents scientifiques de niveau recherche, publiés ou non, émanant des établissements d'enseignement et de recherche français ou étrangers, des laboratoires publics ou privés. 


\title{
Synergies and complementarities of CloudSat-CALIPSO snow observations
}

\author{
A. Battaglia ${ }^{1}$ and J. Delanoë ${ }^{2}$ \\ Received 9 May 2012; revised 4 December 2012; accepted 7 December 2012; published 25 January 2013.
}

[1] Four years (2007-2010) of colocated $94 \mathrm{GHz}$ CloudSat radar reflectivities and $532 \mathrm{~nm}$ CALIPSO Cloud-Aerosol Lidar with Orthogonal Polarization (CALIOP) backscattering coefficients are used to globally characterize snow-precipitating clouds. CALIOP is particularly useful for the detection of mixed and supercooled liquid water (SLW) layers. Liquid layers are common in snow precipitating clouds: overall/over sea/over land $49 \%$ / $57 \% / 33 \%$ of the snowy profiles present SLW or mixed-phase layers. The spatial and seasonal dependencies of our results - with snowing clouds more likely to be associated with mixed phase during summer periods - are related to snow layer top temperatures. SLW occurs within the majority $(>80 \%)$ of snow-precipitating clouds with cloud tops warmer than $250 \mathrm{~K}$, and is present $50 \%$ of the time when the snow-layer top temperature is about $240 \mathrm{~K}$. There is a marked tendency for such layers to occur close to the top of the snow-precipitating layer $(75 \%$ of the times within $500 \mathrm{~m})$. Both instruments can be synergetically used for profiling ice-phase-only snow, especially for light snow $(Z<0$ $\mathrm{dBZ}, S<0.16 \mathrm{~mm} / \mathrm{h}$ ) when CALIOP is capable of penetrating, on average, more than half of the snow layer depth. These results have profound impact for deepening our understanding of ice nucleation and snow growth processes, for improving active and passive snow remote sensing techniques, and for planning snow-precipitation missions.

Citation: Battaglia, A., and J. Delanoë (2013), Synergies and complementarities of CloudSat-CALIPSO snow observations, J. Geophys. Res. Atmos., 118, 721-731, doi:10.1029/2012JD018092.

\section{Introduction}

[2] Snowfall represents an increasingly larger portion of the total precipitation at higher latitudes [Mugnai et al., 2005]. Measuring such precipitation has important hydrological and societal impacts such as forecasting hazardous weather, understanding the hydrological water budget, and the relationship between annual snowfall accumulations and ice sheet dynamics. Snow also represents a conundrum for climate change. Both theoretical arguments and models suggest that net high-latitude precipitation increases in proportion to increases in mean hemispheric temperature. Increased precipitation is the most plausible source for the observed significant increases in river discharge across Eurasia since the 1930s [Peterson et al., 2002]. However, recent findings reported a general decline of the annual total precipitation (rainfall plus snow water equivalent) in the same region [Rawlins et al., 2006].

[3] Despite its importance, accurate measurement of precipitation remains challenging and an accurate large-scale

\footnotetext{
${ }^{1}$ Department of Physics and Astronomy, University of Leicester, University Road LE17RH, Leicester, UK.

${ }^{2}$ LATMOS/IPSL/UVSQ/CNRS, Guyancourt, France.

Corresponding author: A. Battaglia, Department of Physics and Astronomy, University of Leicester, University Rd., LE17RH, Leicester, UK. (a.battaglia@ le.ac.uk)

(C2012. American Geophysical Union. All Rights Reserved. 2169-897X/13/2012JD018092
}

estimation of the snowfall is not yet available. In situ measurement errors for solid precipitation frequently have uncertainties that range from 20 to $50 \%$ due to undercatch in windy conditions, particle shape, and density assumptions [Rasmussen et al., 2012], with very few nonuniform spatially distributed observation sites in remote regions. In contrast, satellite-based active microwave remote-sensing techniques offer a new frontier for monitoring snow by providing vertically resolved precipitating cloud microphysical measurements, cruxes in validating the performance of numerical weather, and climate prediction models. This has been clearly demonstrated by the CloudSat mission [Stephens et al., 2008], which uses a near-nadir-pointing millimeter radar with a surface footprint of about $1.4 \times 1.7 \mathrm{~km}^{2}$. The CloudSat radar does not scan, but generates a curtain of two-dimensional cross-sections through the atmosphere. Latitudes below $81^{\circ} \mathrm{N}$ are heavily sampled, with radar observations equally good during polar day or night conditions. Due to its sensitivity down to $-30 \mathrm{dBZ}$ [Tanelli et al., 2008] the radar captures the vertical structure (resolution of $480 \mathrm{~m}$ ) of clouds and solid precipitation even during relatively light precipitation cases [Liu, 2008; Matrosov et al., 2008; Kulie and Bennartz, 2009]. However, radar-based algorithms rely on statistical relations between the equivalent radar reflectivity factor $Z_{e}$ and snowfall rate, $S$, which are in turn a function of particle fall velocity, particle habit [Petty and Huang, 2010; Kulie et al. 2010], and particle size distribution (PSD) and can lead to uncertainties in snowfall estimate over $100 \%$ [Hiley et al. 2011]. 
[4] On the other hand, existing passive microwave satellite remote sensing techniques while providing much better coverage are hampered by two main issues: (1) for window channels the large uncertainties in surface emissivities, in particular, on ice- and snow-covered surfaces; (2) the presence of supercooled liquid water (SLW) content, which tends to obscure the brightness temperature depression, i.e., the distinctive signature of snow [Wang et al., 2012; Hiley et al., 2011]. The latter problem burdens snow estimates from ground-based passive microwave measurements as well [Löhnert et al., 2011; Kneifel et al., 2010]. The first issue can be mitigated by using higherfrequency (sounding) microwave channels [Bauer and Mugnai, 2003], which are less susceptible to the high variability in surface emissivity while still responding to the snow scattering signatures [e.g., Skofronick-Jackson and Johnson, 2011; Kongoli et al., 2003; Skofronick-Jackson et al., 2004; Surussavadee and Staelin, 2009] verified that microwave radiometric sounders with opaque channels, such as the Microwave Humidity Sounder and the Advanced Microwave Sounding Unit, have the potential for more accurate precipitation retrievals, including snowfall.

[5] The complexity of snow profiling calls for an integrated approach of multifrequency active and passive instruments. In this context, lidar and radar can provide useful complementary information as already demonstrated by ground-based [Wang and Sassen, 2001; Wang et al., 2004; Shupe et al., 2008; de Boer et al., 2011; Westbrook and Illingworth, 2011] observations. Supercooled liquid water, although almost invisible to the radar, is strikingly visible to the lidar as thin but highly reflective layers [e.g., Hogan et al., 2003; Westbrook and Illingworth, 2011; Hu et al., 2010] so that lidar observations offer a straightforward way to infer the presence of SLW and to detect mixed-phase clouds. On the other hand, in the presence of ice-phase-only, the lidar backscattered intensity is approximately proportional to the square of particle diameter because, at lidar wavelengths, snow particles scatter in the geometric optics regime. Conversely, the radar operates in or close (for large snowflakes Mie effects are not negligible, e.g., Liu [2008]) to the Rayleigh scattering regime, and the backscattered power is approximately proportional to the square of particle mass. Thus, in the presence of ice-phase-only, the two instruments are sensitive to two different moments of the snow size distribution. This difference can be used in a synergistic approach to compute a characteristic particle size, once the attenuation and multiple scattering (only relevant for the lidar) has been accounted for [e.g., Delanoë and Hogan, 2008].

[6] This study capitalizes on the DARDAR product of colocated CALIPSO and CloudSat measurements to investigate global distributions/characteristics of snow-precipitating clouds. Specifically, two sets of scientific questions, which are directly related to the complementarity and the synergy of the two instruments, will be addressed:

1. How frequent are SLW and mixed phase layers embedded in snow precipitation? Is there a regional dependence of such a frequency? Where are these mixed-layers typically located and what is their relevance for cloud microphysics? (Complementarity aspect).

2. In the presence of ice-phase-only, how deep can the lidar signal penetrate into the snow layer? Is the lidar attenuation primarily related to the presence of SLW and mixed-phase clouds or to the presence of heavy snow as well? How is the microwave optical thickness related to the visible optical depth of snow-bearing clouds? (Synergy aspect).

[7] The paper is organized as follows: Section 2 describes the data set used in this analysis. A case study is presented to demonstrate the analysis technique. In section 3 general statistics for the relative contribution of ice-phase versus mixed-phase in snowbearing clouds is discussed. In the presence of ice-phase-only, the lidar penetration capabilities are assessed as well. The impact of our findings in relation to snow precipitation processes and radiative transfer studies is discussed in section 4, while conclusions and recommendations for future works are drawn in section 5.

\section{Methodology}

[8] This study aims at analyzing the synergistic potential between the CALIPSO Cloud-Aerosol Lidar with Orthogonal Polarization (CALIOP) [Winker et al., 2007] and the $94 \mathrm{GHz}$ CloudSat radar in snow observations. The DARDAR data set (http://www.icare.univ-lille1.fr/projects/dardar/) [Delanoë and Hogan, 2010] provides an excellent starting point for such a study because: (1) the CloudSat 2B-GEOPROF product and the CALIPSO Lidar Level 1B profile data are colocated and regridded on a common $60 \mathrm{~m}$ vertical grid and horizontally averaged in the CloudSat footprint; (2) a target categorization, which refines the CloudSat [Sassen and Wang, 2008] and the lidar [Mace et al., 2009] feature masks, is provided for each grid point. Of particular relevance for this study is the identification of snow events, which is based on the $2 \mathrm{C}$ PRECIP-COLUMN CloudSat product (http://www.cloudsat. cira.colostate.edu/dataSpecs.php?prodid=93). The profile maximum reflectivity threshold for the identification of snow profiles is set at $-15 \mathrm{dBZ}$. As demonstrated in Hiley et al. [2011] the selection of this threshold slightly affects snowfall frequency and only marginally snowfall accumulation. In an attempt to exclude nonprecipitating profiles and reduce ground clutter contamination, a vertical continuity test is introduced for profiles over land; reflectivity must exceed $-15 \mathrm{dBZ}$ in the five CloudSat bins above the near surface bin. Over oceanic areas the same test is not applied to avoid the removal of real shallow features [Kulie and Bennartz, 2009]. Finally, to avoid contamination by events with partially melted hydrometeors, snowfall cases are required to have a European Center for medium-range weather forecast (ECMWF) $2 \mathrm{~m}$ temperature below $0{ }^{\circ} \mathrm{C}$.

[9] For the profiles identified as snowy, the radar backscattering profile is used to identify the snow layer, i.e., the lowest layer above the surface with significant cloud profiling radar (CPR) detection. The top of such layer is identified from now

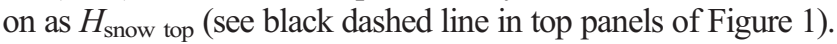
Cloud layers containing SLW (magenta crosses in the top left panel of Figure 1) are identified by the methodology implemented by Delanoë and Hogan [2010] based on previous work on target classification from ground-based CloudNet measurements [Illingworth et al., 2007]. This methodology differs from the one adopted in $\mathrm{Hu}$ et al. [2009] while a similar technique has been already used by Hogan et al. [2004] and by Zhang et al. [2010] to estimate the global distribution of stratiform SLW clouds using the lidar in-space technology experiment (LITE) space-borne lidar and the CloudSat and CALIOP combination, respectively. The current criterion is capable of 

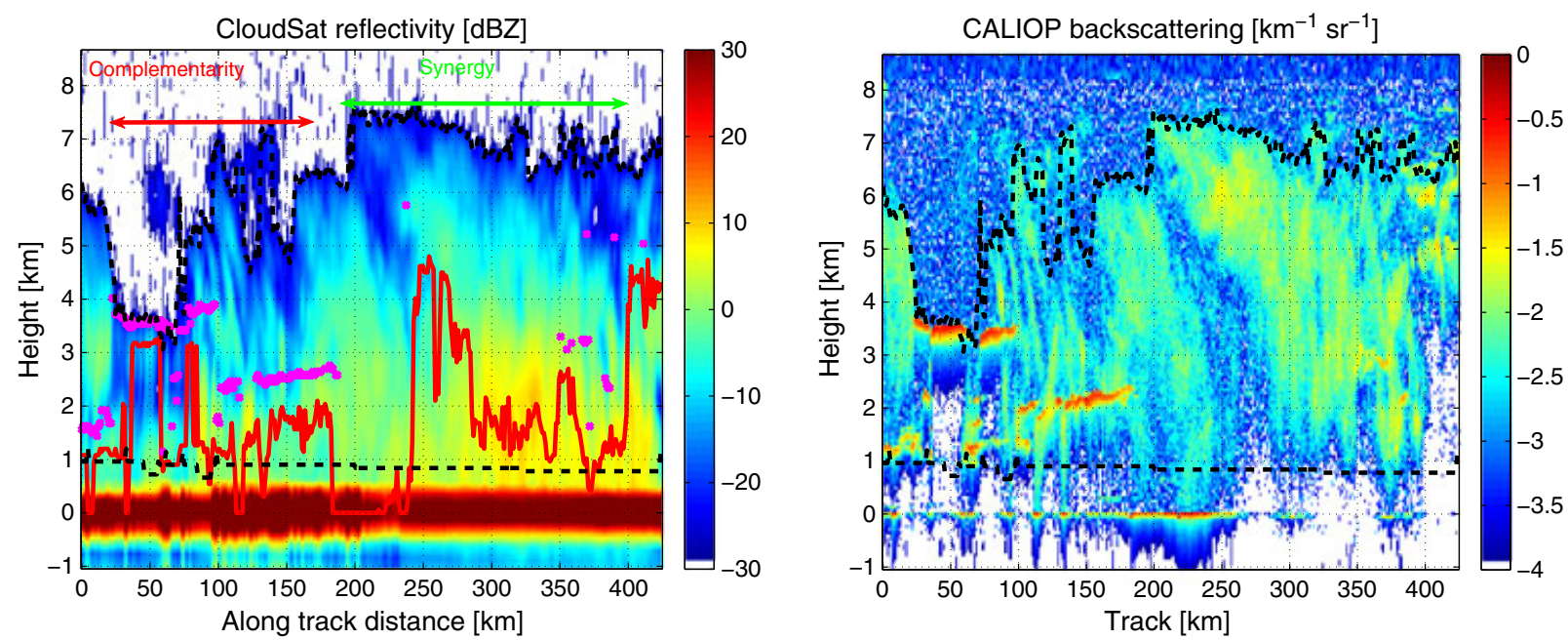

DARDAR classification
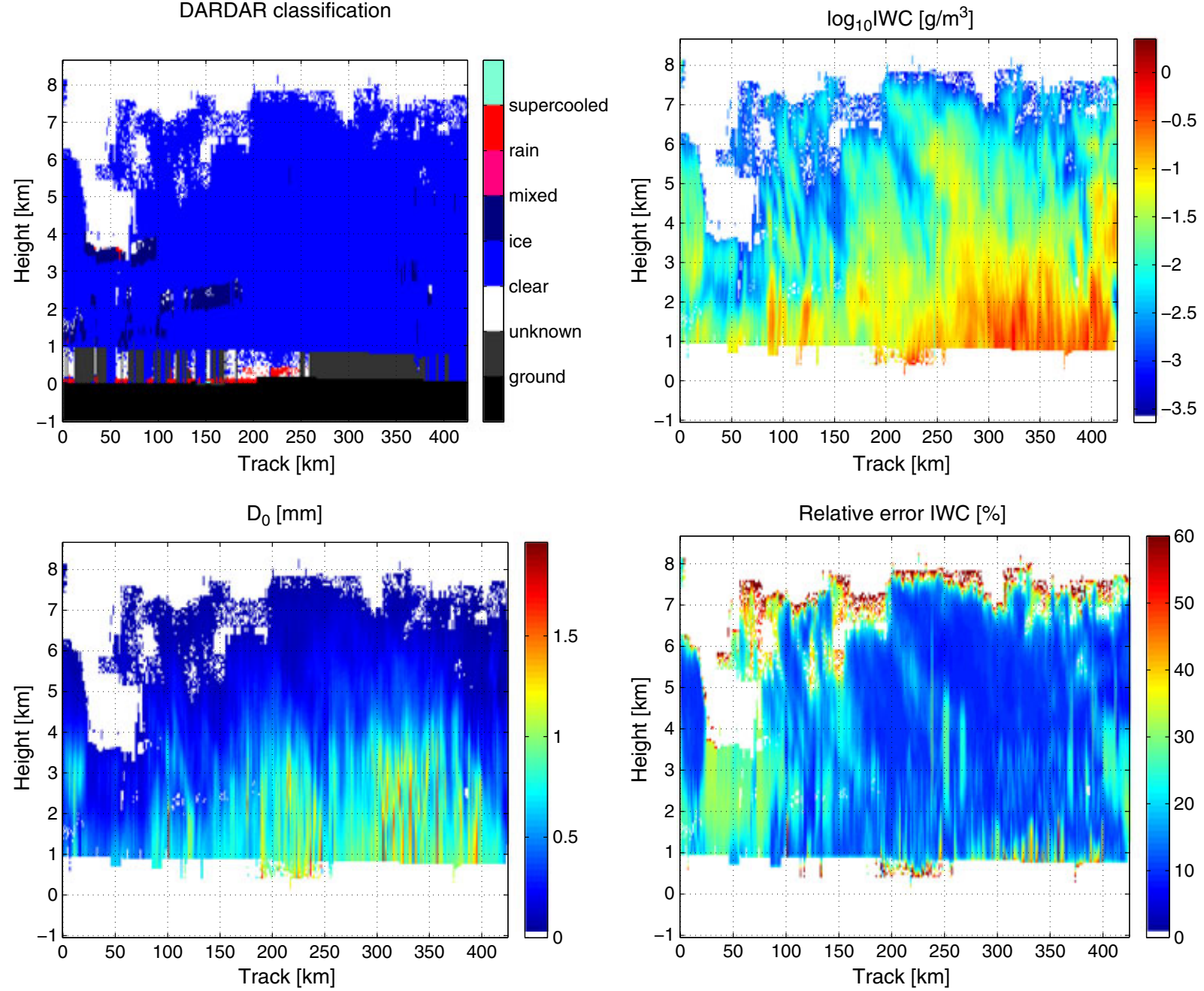

Figure 1. A snow event occurred on 29 November 2007, in the Arctic Ocean. (top panels) CloudSat reflectivity and CALIOP backscattering vertical profiles. The black dashed lines mark the CloudSat confident detection boundaries while the continuous red line corresponds to the maximum penetration level for CALIOP. Crosses correspond to mixed phase or SLW top layers. (middle and bottom panels) Classification index (center left), IWC (center right), $\boldsymbol{D}_{\mathbf{0}}$ (bottom left), and $I W C$ relative error (bottom right) from the DARDAR data set. 
detecting very thin SLW cloud layer with integrated water path as low as $3.8(7.6) \mathrm{g} / \mathrm{m}^{2}$ (based on the assumption of liquid-water effective radii equal to $10(5) \mu \mathrm{m}$ ), which corresponds (see analogous formula (3) for ice later on) to an optical thickness of 1.15 (i.e., to a two-way attenuation of $10 \mathrm{~dB}$ ). With the same token, integrated SLW paths greater than $15-30 \mathrm{~g} / \mathrm{m}^{2}$ do produce two-way attenuation higher than $40 \mathrm{~dB}$ and are therefore enough to obscure any underlying layer.

[10] A snow precipitating cloud is presented in Figure 1. Because CloudSat reflectivity is only marginally affected by attenuation [Hiley et al., 2011] and multiple scattering [Matrosov and Battaglia, 2009] in snowy conditions, the measured reflectivity practically corresponds to the effective reflectivity. The event is a light snow event with close to surface reflectivities ranging between -10 and $8 \mathrm{dBZ}$, which according to the $Z-S$ relationship proposed by [Kulie et al., 2010] $\left(Z=13.16 S^{1.4}\right)$ correspond to snow rates between 0.03 and of $0.5 \mathrm{~mm} / \mathrm{h}$. Note the clutter contamination close to the surface, which does not allow any retrieval below $1 \mathrm{~km}$ (dashed line in top left panel). The CALIOP backscattering profiles on the other hand show strong attenuation especially in correspondence to the layer at $3.5 \mathrm{~km}$ altitude between 20 and $100 \mathrm{~km}$ and to the layer at $2 \mathrm{~km}$ between 100 and $175 \mathrm{~km}$. The strong lidar return (which has no correspondence in the radar reflectivity) is an unambiguous signature of liquid water cloud as correctly identified by the DARDAR mask algorithm. The lidar lower boundary detection line (red line in the top left panel) tends to stay within $1 \mathrm{~km}$ from the top height of these layers, which suggests complete attenuation of the lidar signal. Pulse stretching is expected here due to multiple scattering [Pounder et al., 2012]. However, in some cases (for instance around $115 \mathrm{~km}$ ), the presence of liquid particles does not produce enough attenuation to completely attenuate the signal, a signature of SLW paths of the order of only few $\mathrm{g} / \mathrm{m}^{2}$. Note that while the first layer appears at the top of the snow the second one is intermingled within the snow cloud. When only ice-phase is detected (at ground-track distances larger than $200 \mathrm{~km}$ ) the lidar penetration depth is highly variable with regions where the lidar is fully penetrating down to the surface and others where the lidar signal can be completely extinguished already in the upper levels. For these situations it is possible that mixed-phase layers at low levels are missed by the classification mask because the threshold that triggers the detection algorithm is imposed on unattenuated backscattering coefficient and the reconstruction of such unattenuated backscattering is troublesome. This will result in an underestimation of the frequency of occurrence of SLW. In general it is only possible to confidently identify one liquid layer in each profile (the highest one). Future studies combining ground-based and space-borne statistics should quantify such an underestimation. It should be noted that the highest layer in a profile is usually the one that influences the TOA radiative fluxes the most [Hogan et al., 2003] and has the greater relevance also in affecting space-borne microwave brightness temperature [Wang et al., 2012].

[11] The DARDAR retrieval can be applied to the combined radar and lidar measurements to produce ice water content (IWC)

$$
I W C \equiv \int M_{\mathrm{ice}}(D) N(D) \mathrm{d} D
$$

and extinction

$$
\alpha \equiv \frac{1}{2} \int A_{\text {ice }}(D) N(D) \mathrm{d} D,
$$

where $D$ is the maximum diameter, $M_{\text {ice }}(D)$ is the mass-size relationship, $A_{\text {ice }}(D)$ is the corresponding area-size relationship and $N(D)$ is the PSD. Effective radius is derived from these two above variables

$$
r_{\mathrm{e}} \equiv \frac{3}{2} \frac{I W C}{\rho_{\text {ice }} \alpha},
$$

where $\rho_{\text {ice }}=0.917 \mathrm{~g} / \mathrm{cm}^{3}$ is the solid ice density. The retrieval technique of Delanoë and Hogan [2010] uses the optimal estimation framework and relies on lookup-tables linking the measurements to ice clouds properties. It assumes a microphysical model describing the shape of the PSD using the normalized approach [Delanö et al., 2005]. The microphysical model assumes relationships for $A_{\text {ice }}(D)$ and $M_{\text {ice }}(D)$ derived from [Brown and Francis, 1995] and [Francis et al., 1998], respectively. Radar reflectivity is computed using the previous assumptions and a $T$-matrix approach assuming an aspect ratio of 0.6 for the ice particles [Hogan et al., 2012].

[12] Results for $I W C$ and $D_{0}$ are plotted in the center-right and bottom-left panels of Figure 1, respectively. $D_{0}$ is the median volume diameter derived from $D_{\mathrm{m}}$ by using the previous assumptions and a value $\mu=1$ for the shape parameter in the $\Gamma$ function [see also Hogan et al., 2003, Figure 12]. This is the typical parameter to characterize the snow size from radar observations. The retrieval algorithm fully exploits both active instrument signals only in absence of liquid phase. Below the first liquid water layer detected, the ice phase is characterized by the radar signal only. In such situation and when the lidar is fully attenuated, the results are obviously affected by larger uncertainties (the one associated with a radar-only retrieval), as clearly demonstrated by the $I W C$ relative error derived from the optimal estimation theory, [Delanoë and Hogan, 2008] (see bottom-right panel in Figure 1). Finally note that in some regions (e.g., between 200 and $250 \mathrm{~km}$ ) the lidar is actually allowing the retrieval to be applied for pixels closer to the surface than those classified as clutter-free by the radar.

\section{Data Analysis: Results and Discussion}

[13] We now explore the potential of the CALIOP lidar first to characterize the presence, location, and amount of supercooled liquid water content (SLWC; complementarity aspect) and then to penetrate precipitating clouds with the possibility of improving radar-only profiling techniques (synergy aspect).

\subsection{Complementary Aspect}

\subsubsection{Occurrence of Mixed-Phase Within Snow Precipitation}

[14] The DARDAR classification scheme can be used to identify SLW/mixed phase layers, thus to compute the percentage of snow events occurring without the presence of mixed phase and/or SLW (i.e., via ice-phase-only). It is worthy of note that, because the procedure for the identification of the presence of liquid layers is based on a decision tree approach, the retrieval procedure is not capable of providing error estimates like the one produced for $I W C$ or $r_{\mathrm{e}}$ (bottom right panel Figure 1). The quantification of errors in the classification scheme is an area of active research; given the 
lack of large verification in situ data, the only plausible way to do that is via sensitivity studies within a simulation framework (like the EarthCARE-simulator) but with the obvious drawback of representing the actual natural variability within the ensemble of the simulated scenes. From now on all statistics are conditional to the presence of snow detected according to the procedure previously described. Four years (2007-2010) of data have been used to build the global statistics of the probability of liquid water clouds for snowprecipitating clouds defined as the ratio between the number of snow precipitation clouds with mixed phase and/or SLW and the number of snow precipitation clouds (see Figure 2). As a reference, Hu et al. [2010] in their Figure 9 produced

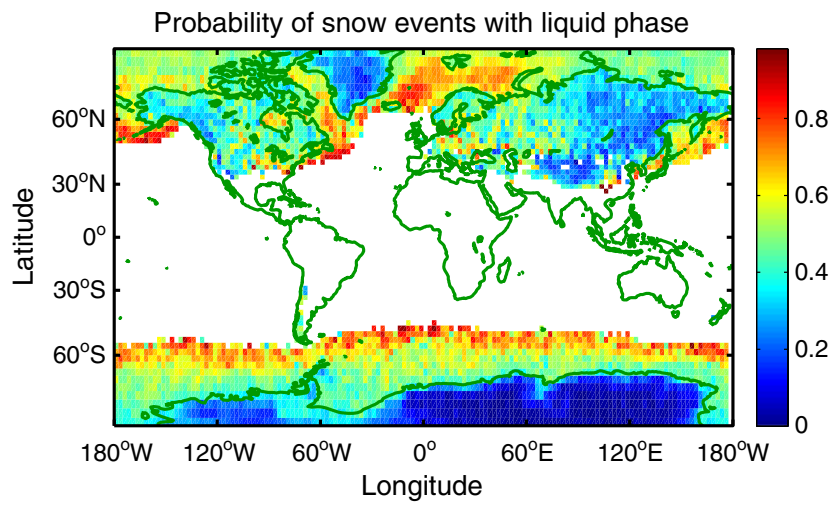

Figure 2. Global distribution of the probability of supercooled water clouds for snow-precipitating events binned in $\mathbf{2 . 5 ^ { \circ }} \times \mathbf{2 . 5 ^ { \circ }}$ boxes. Results are presented only for pixels with a minimum of 500 counts.

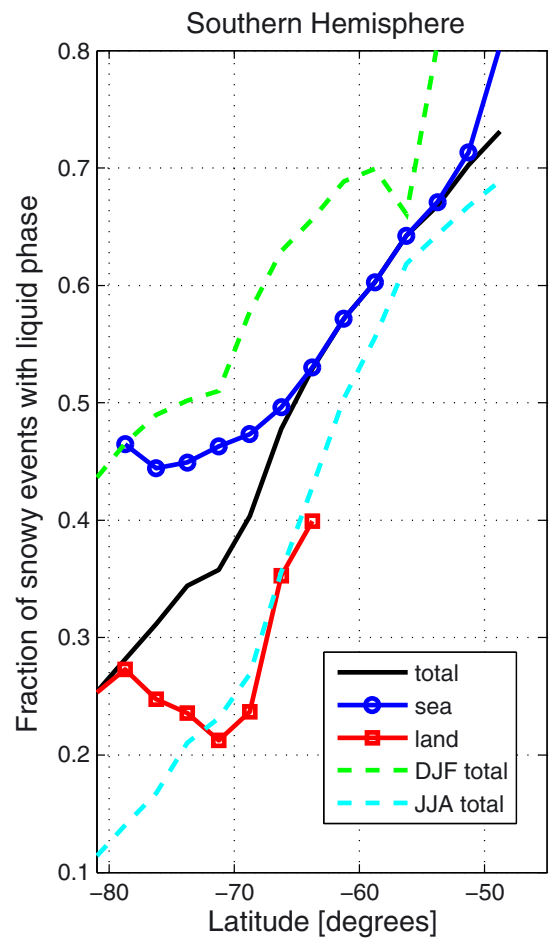

the probability distribution of SLWC for generic cloudy condition (and for 2008 only). No significant change in the following statistics has been noticed following the CALIOP's tilt, which occurred in November 2007. Clearly there is a strong regional dependence with a marked land versus sea contrast with snow events occurring over ocean more likely to involve the liquid phase. Overall $49 \%$ of the snowy profiles do present SLW or mixed-phase layers. This percentage moves to $57 \%$ and $33 \%$ over sea and over land surfaces, respectively. The Antarctica continent, Greenland, Alaska, Siberia, and the Himalaya are the regions where snow is occurring more frequently via ice-phase-only. On the other hand the eastern part of the United States and some region in east Europe/west Russia seems to have more pronounced presence of mixed phase compared to continental regions at similar latitudes.

[15] A zonal plot with the fraction of snowy profiles with presence of liquid phase is shown in Figure 3. Snow events occurring over sea are significantly more prone to the presence of the liquid phase while the Antarctica continent (latitudes lower than $-64^{\circ}$ ) stands out as the region where snow occurs most frequently via ice-phase-only processes $(73 \%)$. While in the Southern Hemisphere there is a strong zonal gradient (due to a strong gradient in the sea-land distribution) with a fraction of events with liquid phase ranging from $28 \%$ to $72 \%$ passing from Antarctica to the South Pacific ocean, in the Northern Hemisphere results are less zonally dependent with only a slight increase of the fraction moving from the North Pole southward over sea and over land (square and circle lines in the right panel in Figure 3). A strong seasonal cycle is present as well; for instance, in the Southern Hemisphere, the austral winter is characterized by significantly less SLW than the austral summer. Figure 3

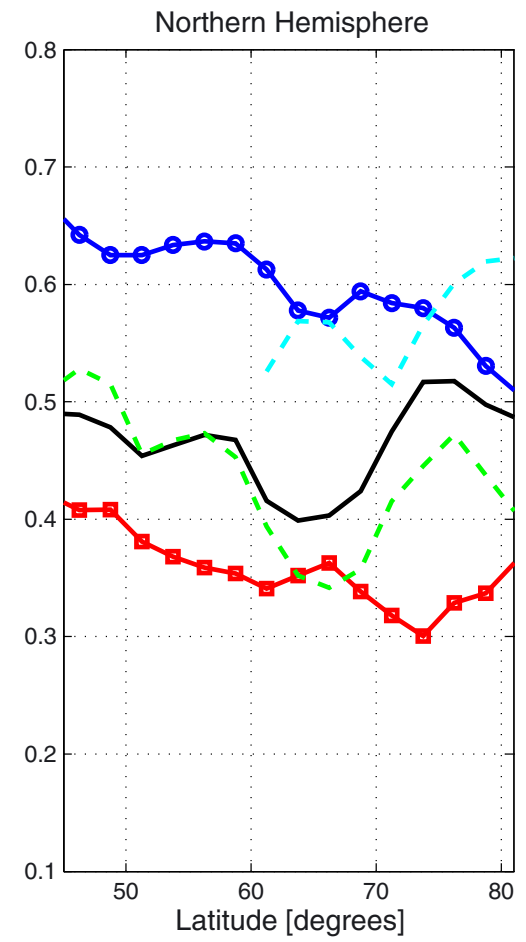

Figure 3. $2.5^{\circ}$ zonal average for the fraction of snowy events with presence of liquid phase in their profiles. Results are presented only for bins with a minimum of 5000 counts. 
can be used to verify if numerical models capture the sea/land contrast and the seasonal variability.

[16] The spatial dependence of Figure 2 and the zonal and sea/land contrasts of Figure 3 are certainly related to cloud temperatures, with warmer cloud temperatures obviously being more favorable for the presence of mixed-phase clouds, and, less certainly, by aerosol effects. This is demonstrated by Figure 4 where the fraction of snow-bearing clouds with liquid-phase as a function of the cloud top temperature (here identified as the temperature of the top of the snow layer as detected by the radar) is plotted. Note that here we do not characterize the presence of the liquid phase with the liquid layer top temperature because this information is not available in radar-only retrievals. Clearly at colder temperatures the probability of finding SLW particles becomes increasingly smaller. Note that while some liquid-phase clouds are still detected for snow systems having cloud top temperatures below $230 \mathrm{~K}$ such cloud layers are actually located at warmer temperatures. Due to homogeneous freezing of cloud droplets at these very cold temperatures no liquid phase is detected below $230 \mathrm{~K}$. Land and sea surfaces show very similar patterns. Only for sea events, the fraction seems to be systematically biased toward larger values, i.e., given the same temperatures of the snow-layer top, events over sea have a tendency to produce slightly more liquid-phase clouds. This is consistent with the findings in $\mathrm{Hu}$ et al. [2010, Figure 6c]. This may be ascribed to the two different aerosol/thermodynamic/dynamic environments. Over land there are very few cases of snow events with snow layer top temperature above $264 \mathrm{~K}$. In fact the vertical continuity test introduced to reduce ground clutter contaminations (see section 2) tends to cut out shallow system with warmer snow layer top. Potentially, such a procedure hampers the detection of shallow events. Because these events are also the warmest, the overall fraction of liquid-phase contaminated snow profiles over land is deemed to be slightly underestimated.

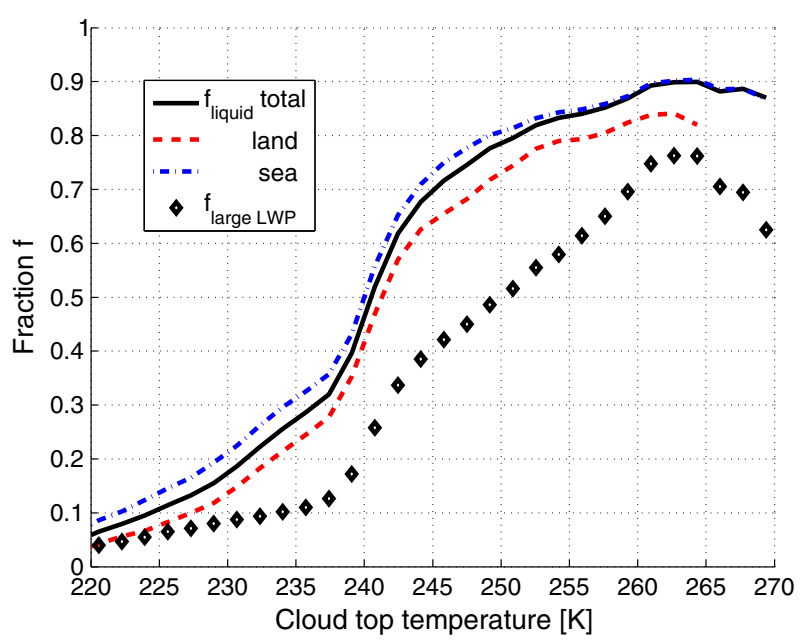

Figure 4. Fraction of snow precipitating clouds with liquid-phase as a function of the temperature of the top of the snow layer as detected by the radar. Diamond line: fraction of liquid-phase layers with large integrated LWC (see text for details) as a function of the temperature of the top of the liquid-phase layer as detected by the lidar. Results are presented only with a minimum of 1000 counts for temperature bin.

\subsubsection{Location of Supercooled/Mixed Phase Layers}

[17] The location of SLW and mixed-phase layers within snow precipitating systems is quite important to investigate their radiative properties. Figure 5 represent the probability density function (pdf) of SLW (continuous) and mixedphase (dashed) top layer heights with reference to the snow layer height (as identified by CloudSat). Both distributions peak around zero, which confirms findings from several authors that SLW and mixed-phase layers tend to occur at the top of cold clouds, where, more likely, entrainment, shear, and radiative cooling tend to induce updraft formation [Rauber and Tokay, 1991]. SLW clouds (red color in the DARDAR mask panel of Figure 1) can be found also above the snow layers (but only in $12 \%$ of the cases they are located at distances larger than $1 \mathrm{~km}$ from the snow layer top) while mixed phase clouds (dark blue color in the DARDAR mask panel of Figure 1) occur $75 \%$ of the time within $500 \mathrm{~m}$ from the snow layer top. As already discussed this estimate is potentially fraught by misdetection issues, although multilayered mixed-phase cloud scenes are also observed. Note that while the mixed phase layers are typically present below the top of the snow layer, they rarely occur above the snow layer (e.g., with $H_{\text {mixed top }}-H_{\text {snow top }}>2 \mathrm{~km}$ ).

[18] From our statistical analysis liquid-phase clouds often consisted of a shallow, cloud-top layer; this makes space-borne configurations ideal to provide statistics of supercooled $/ \mathrm{mixed}$ phase layer occurrences, with not much obscuration by intervening cloud.

\subsubsection{Amount of Liquid Water Path (LWP)}

[19] In some cases, the lidar signal is capable of penetrating through the liquid layer, an indication of small liquid water path (LWP). By adopting a rough categorization criterion, liquid-phase clouds have been classified as bearing a large LWP (as a rule of thumb larger than $20 / 30 \mathrm{~g} / \mathrm{m}^{2}$ ) when the lidar signal is fully attenuated within $1 \mathrm{~km}$ from the liquid layer cloud top. The frequency of occurrence of such layers (defined as the ratio between the number of snow precipitation clouds with large LWP and the number of snow precipitation clouds) is plotted in Figure 4 (diamond line) as a

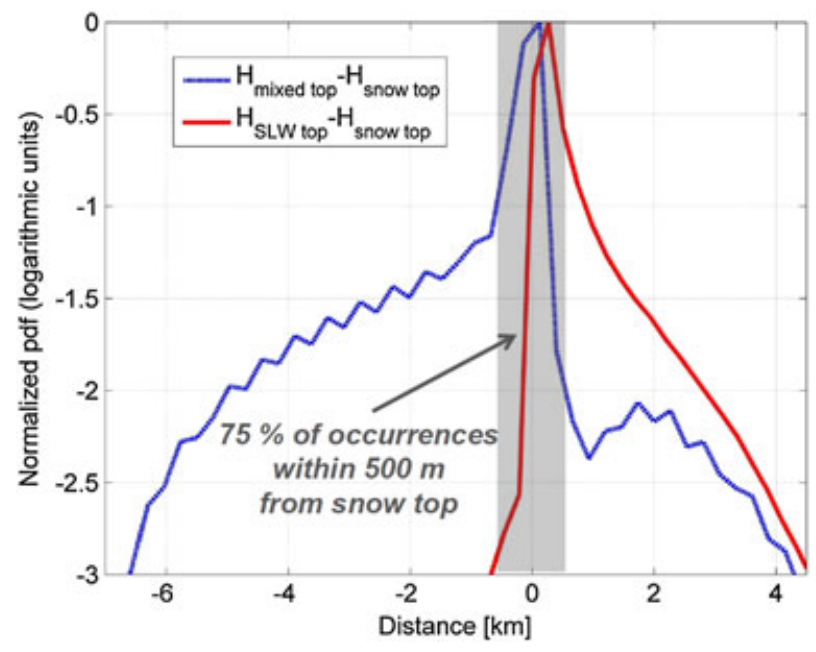

Figure 5. Distribution of cloud top location occurrences (in logarithmic scale) for SLW and mixed-phased layer relative to the snow layer top height. 
function of the temperature of the top of the liquid-phase layer as detected by the lidar. At colder temperatures SLW contents are generally smaller, in agreement with theoretical prediction of condensate supply rates decreasing at higher altitudes and colder temperatures [Rauber and Tokay, 1991; Hu et al., 2010]. Overall, at least $36 \%$ of the liquid-phase clouds are characterized by small liquid contents. In fact, while the strong attenuation can also be caused by ice particles, it is certainly true that if the lidar signal is detectable well within the snow layer, then the LWP has to be relatively small. The discussion here is purely qualitative; inversion techniques for the derivation of SLWC profiles from the lidar return are a topic of current research [Pounder et al., 2012].

\subsection{Synergy Aspect: Penetration Depth of Lidar in Presence of Ice-Phase-Only}

[20] In the situation of ice-phase-only snow the lidar can sometimes penetrate deeply into the snow layer. This is demonstrated in Figure 6 where the fraction of vertical profiles where both CALIOP and the CPR backscattering returns are detectable is plotted as a function of maximum profile reflectivity (which is a proxy of the surface snow rate). Note that the lidar signal is considered here "detectable" if the SNR is greater than 3. Clearly for light snow $(Z<0 \mathrm{dBZ}$, $S<0.16 \mathrm{~mm} / \mathrm{h}$ ) the lidar can on average penetrate almost $50 \%$ of the vertical profile. Because of pulse stretching originating from multiple scattering [Hogan and Battaglia, $2008]$ this value can be overestimated. Notional results (not shown) demonstrate that the pulse stretching occurs for a system having an integrated backscattering profile of at least $0.01 \mathrm{sr}^{-1}$ with a maximum pulse stretch of about $500 \mathrm{~m}$ for a profile having integrated backscattering equal to $0.03 \mathrm{sr}^{-1}$. Heavier snowstorms tend to produce more attenuation in the lidar signal with the percentage dropping to $30 \%$ for heavy snowfall. Note also the presence of a considerable number of profiles where the lidar is not capable of penetrating at all in the snow layer (Figure 6, region at the bottom with $f$ values lower than 0.1). This is most frequently due to a thick ice layer

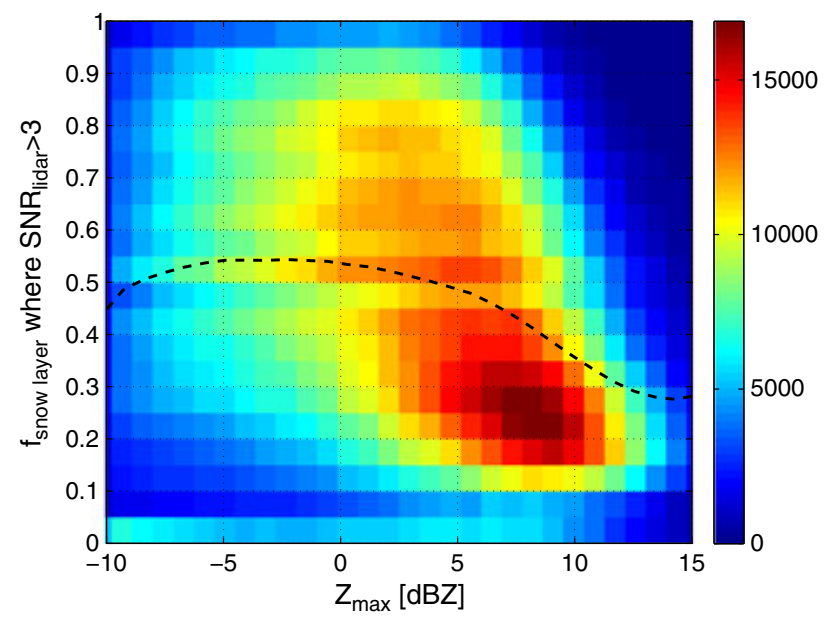

Figure 6. Two-dimensional occurrence histogram of the fraction of the snow layer (as identified by the CloudSat radar) where the lidar signal-to-noise ratio is larger than 3 as a function of the maximum radar reflectivity within the snow layer. Only ice-phase snow-precipitating profiles are considered. The dashed line corresponds to the mean value. that is obscuring the underlying snow layer and less frequently to misclassification and/or inhomogeneity of the CloudSat footprint and/or clutter CPR-related artifacts.

[21] In general, the penetration depth (which is related to the visible optical thickness of the snow system) can be completely different for systems having similar vertical reflectivity structures. Figure 7 depicts a two-dimensional occurrence histogram of the penetration depth as a function of the integrated reflectivity from the top to the bottom of the snow layer, defined as

$$
I_{Z} \equiv \int_{H_{\text {snow }}}^{H_{\text {snow }}} \quad{ }_{\text {bot }}^{\text {top }} Z(h) \mathrm{d} h .
$$

[22] The integral (4) is expressed in linear units $\left[\mathrm{mm}^{6} / \mathrm{m}^{2}\right]$. Recalling the definition of $\mathrm{dBZ}$, we use $\mathrm{dBZ}_{\text {int }}$ as a unit for $10 \log _{10}$ of the integrated reflectivity. Such quantity is roughly a proxy for the scattering optical thickness at $94 \mathrm{GHz}$ [Battaglia et al., 2011]. The large variability in correspondence to the same integrated reflectivity present in Figure 7 is again an indication of the two completely different scattering cross-sections in the visible and in the $3 \mathrm{~mm}$ microwave region, which indirectly pinpoints at the utility of the two simultaneous measurements.

\section{Discussion}

[23] The previous findings are extremely important to get a better insight with respect to two main research avenues.

\section{Cloud Microstructure and Snow Precipitation Processes}

[24] The existence of an SLW layer near the top of cold clouds is a unique environment for ice crystal nucleation via contact and/or condensation freezing nucleation and early diffusional growth of ice crystals via the BergeronFindeissen process [Pruppacher and Klett, 1997]. Ice crystals forming in the liquid layer experience an environment that is slightly above water supersaturation and will develop habits characteristic of that environment (e.g., dendrites, sector plates, sheaths and needles, see Pruppacher and Klett

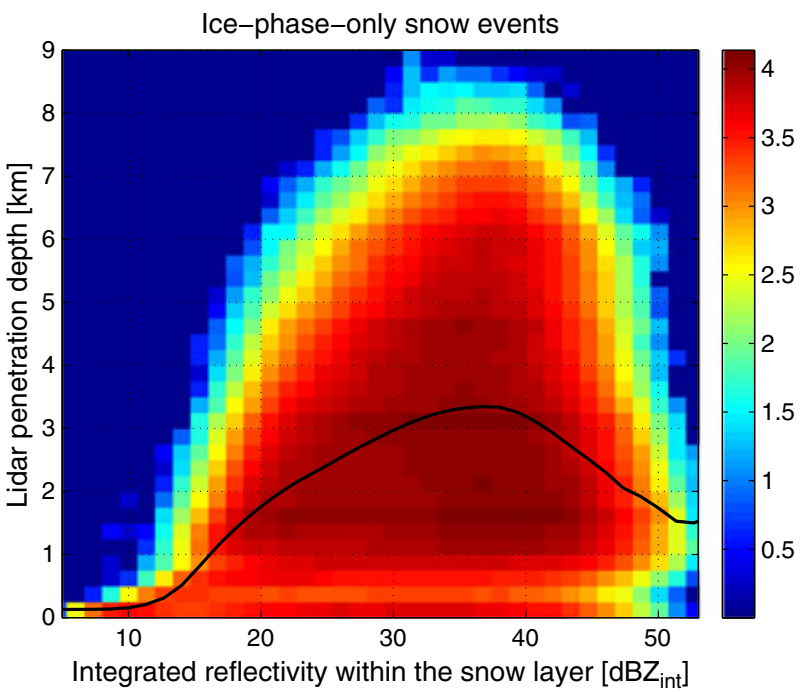

Figure 7. Two-dimensional $\log _{10}$ (occurrence) histogram of the penetration depth as a function of the integrated reflectivity from the top to the bottom of the snow layer. 
[1997]). Because these habits activate specific growth mechanisms, significant changes in ice particle concentration habits and growth mechanisms could occur in the whole cloud depending on the presence or absence of a liquid layer near the cloud top. Figure 8 clearly demonstrates different pdf of events occurring with ice-phase-only and in the presence of liquid-phase. Note the strong cutoff at $-15 \mathrm{dBZ}$, which comes from the profile maximum reflectivity threshold introduced in the 2C-PRECIP-COLUMN algorithm for the identification of snow profiles. There is a clear tendency of heavy snowfall events to occur via ice-phase-only processes with a peak in the distribution for ice-phase-only (liquidphase) events around a close-to-surface reflectivity of $5(-5)$ $\mathrm{dBZ}$, which roughly corresponds to $0.4(0.8) \mathrm{mm} / \mathrm{h}$. This contrast seems to be much more prominent for events over

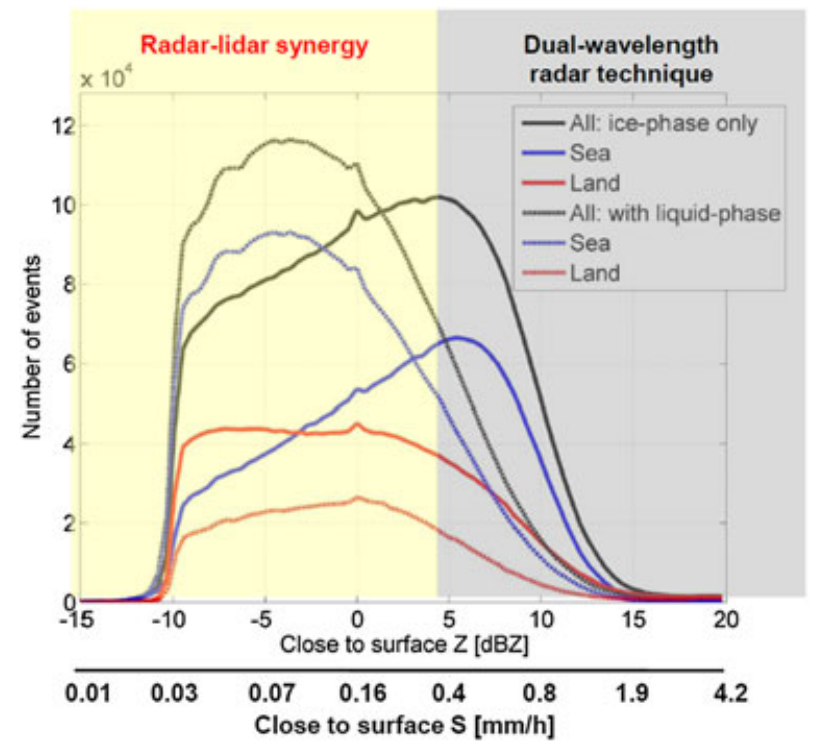

Figure 8. Histogram of 2007 snow events classified as icephase-only (continuous lines) and with presence of SLW and/or mixed phase (dashed lines) as a function of the close-to-the-ground reflectivity. The two subsets of events over sea and over land are plotted as well. Indicative values of the snow rate at the ground as derived from $Z=\mathbf{1 3 . 1 6} S^{\mathbf{1 . 4}}$ [Kulie et al., 2010] are also reported. sea. Similar findings derived from an analysis based on AMSR/E data (ocean-only) are reported by [Wang et al., 2012], with the heaviest snowfall typically associated to the ice-phase-only clouds. Quite frequently, the cloud top appears as a primary source of ice crystals, with high reflectivity fall streaks originating from there [Westbrook et al., 2010]. This demonstrates potential correlations between the above liquid and the ice formation underneath. To have a better understanding of the microphysical processes contour frequency altitude displays (CFADs) of the reflectivity profiles rescaled to the snow cloud top (1) for the ice-phase-only profiles and (2) for profiles involving mixed or SLW layers within $500 \mathrm{~m}$ from the snow cloud top are plotted in the left and right panels of Figure 9, respectively. It is clear that, because of highly supersaturated conditions, there is an enhanced ice crystal growth process in the presence of SLW clouds. This is epitomized by the slopes of the mode of the CFADs in the first half kilometer below the snow layer top, roughly equal to $10 \mathrm{dBZ} / \mathrm{km}$ and $22 \mathrm{dBZ} / \mathrm{km}$ for the ice-phase-only and the mixed-phase, respectively. The presence of SLW clearly induces the production of precipitation-sized particles more rapidly than if nucleation was to occur in a purely ice-saturated environment. The apparent contradiction between this conclusion and the fact that ice-phase-only processes produce actually larger snow-rates has to be ascribed to the difference in depth of the snow precipitating systems. While systems involving the liquid phase are the shallower (having in fact warmer cloud tops) with a pdf for the snow system thickness peaking around $1 \mathrm{~km}$ and a mean of $2.4 \mathrm{~km}$, the snow systems with ice-phase-only are typically much deeper with a pdf peaking at about $4 \mathrm{~km}$ and a mean value of $4.4 \mathrm{~km}$.

\section{Radiative Studies}

[25] Liquid layers produce brighter returns in the $0.532 \mu \mathrm{m}$ lidar channel than ice clouds (see again Figure 1). This epitomizes the fact that a given mass of cloud condensate produces a much larger optical thickness (at visible wavelengths) when distributed in the liquid phase than in the ice phase [Hogan et al., 2003]. As an immediate consequence SLW and mixed-phase clouds play a crucial role in the shortwave radiation budget with strong impact for radiative climaterelated studies. The effects of phase on IR radiation are nonnegligible as well. Very recently, Waliser et al. [2011]
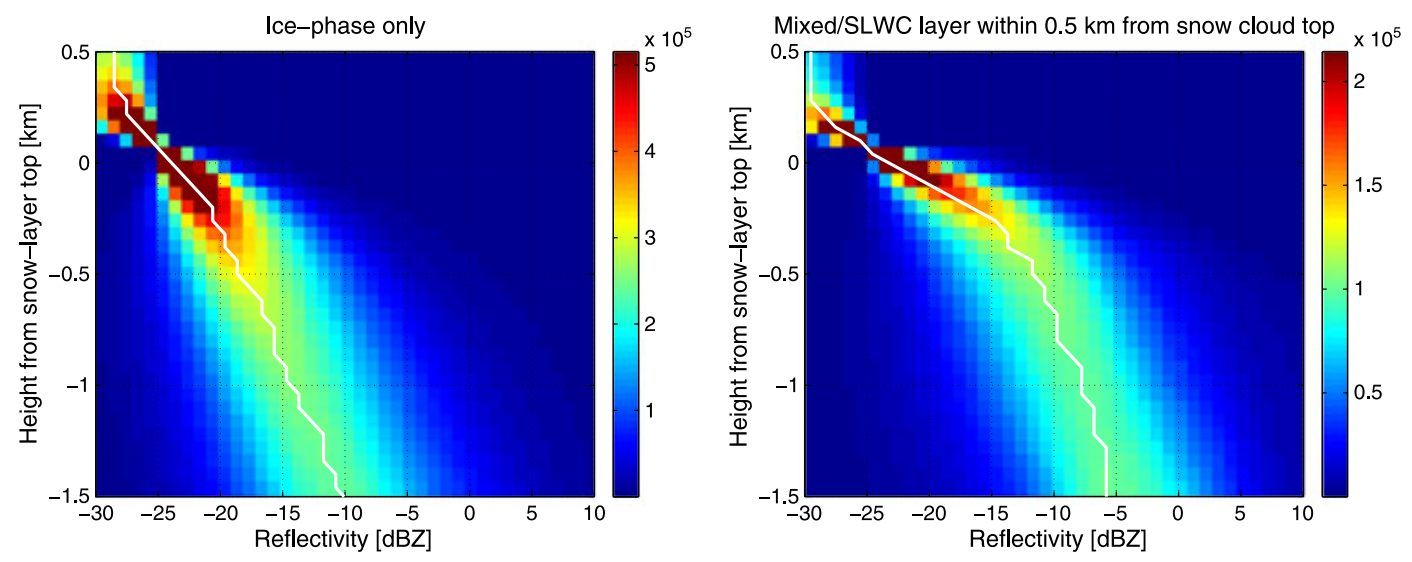

Figure 9. CFADS of reflectivity vs height below snow-layer top for snow events with ice-phase-only (left) and with occurrence of liquid phase within $500 \mathrm{~m}$ from the snow layer top (right). 
highlighted the relevance of the radiative impact of precipitating ice as compared to suspended ice. An accurate quantification of the effects of snow precipitating clouds at high latitudes requires a full characterization of the mixed-phase as well. The data set presented in this paper offers the opportunity for validating the representation of snow precipitating clouds in climate models.

[26] Supercooled liquid water has a strong impact on passive microwave satellite remote sensing measurements as well. At high microwave frequencies $(>35 \mathrm{GHz}$ ) dry snow behaves like a perfect scatterer while liquid water droplets are almost perfect absorbers/emitters. As a consequence snow and SLW produce completely different signatures in passive microwave satellite measurements, with, most of the time, opposite contributions to brightness temperatures. Wang et al. [2012] demonstrated by radiative transfer simulations that the snow brightness temperature depressions are masked by the presence of SLW. While the SLW signal completely overcomes the snow signature at $37 \mathrm{GHz}$ and partially at $85 \mathrm{GHz}$ for typical LWP values, LWP contents of the order of $50-100 \mathrm{~g} / \mathrm{m}^{2}$ can significantly affect higher frequencies $(166 \mathrm{GHz})$ as well. Thus, the characterization of the liquidphase within snow-precipitating clouds is mandatory also for microwave-related precipitation studies.

\section{Conclusions and Future Work}

[27] The combined CloudSat-CALIOP data set offers an unprecedented opportunity to conduct studies for the characterization of snow-precipitating clouds: while the CloudSat radar represents a unique snow detector with profiling capabilities, the CALIOP lidar characterizes the presence of mixed and SLW layers (complementarity aspect) and has the potential to provide additional profiling information in the presence of ice-phase-only snow (synergy aspect).

\subsection{Complementarity Aspect}

[28] This work exploits four years (2007-2010) of colocated data to show that liquid layers are common in snow-precipitating clouds, especially in the ocean environment. Overall, $49 \%$ of the snowy profiles does present SLW or mixed-phase layers. Due to lidar attenuation problems this estimate is likely to be underestimated. This percentage moves to $57 \%$ and $33 \%$ over sea and over land surfaces, respectively. The Antarctica continent, Greenland, Alaska, Siberia, and the Himalaya are the regions where snow is occurring more frequently via ice-phase-only. The spatial and seasonal dependencies of our results - with snowing clouds more likely to be associated with mixed phase during summer periods - are related to snow layer top temperatures, with the probability of finding SLW particles becoming increasingly smaller at low temperatures, consistent with the fact that below $235 \mathrm{~K}$ homogeneous freezing of water droplets occurs. Supercooled liquid water occurs within the majority $(>80 \%)$ of snowprecipitating clouds with cloud tops warmer than $250 \mathrm{~K}$, and is present $50 \%$ of the time when the snow-layer top temperature is about $240 \mathrm{~K}$. This has important consequences for understanding ice nucleation processes, which seem to occur predominantly via the liquid phase at temperatures greater than $250 \mathrm{~K}$, a finding common to other recent studies for midlevel midlatitude clouds [e.g., Westbrook and Illingworth,
2011]. Moreover, SLW and mixed-phase layers tend to occur at the top of snow-precipitating clouds $(75 \%$ of the times within $500 \mathrm{~m}$ from the snow layer top), in agreement with theoretical predictions and observations at ground-based sites. Within liquid-topped ice clouds a rapid ice crystal growth is promoted via the Bergeron-Findeison mechanism, with an increase in reflectivity in the first $500 \mathrm{~m}$ below the mixed-phase layer, which is more than doubled compared to that occurring within ice-phase-only snow layers.

[29] Future work should aim at better assessing the potential of lidar for liquid layer detection by quantifying missed detections, false alarms, and indices like the equitable threat score for different scenarios, different liquid water path detection thresholds and different instrument configurations (e.g., ground-based vs space-borne).

\subsection{Synergy Aspect}

[30] In the situation of ice-phase-only snow, the lidar can sometimes penetrate deeply into the snow layer. In the presence of ice-phase-only for light snow $(Z<0 \mathrm{dBZ}, S<0.16 \mathrm{~mm} / \mathrm{h})$ the lidar can, on average, penetrate almost $50 \%$ of the vertical profile. Heavier snowstorms tend to produce more attenuation in the lidar signal with the percentage dropping to $30 \%$ for heavy snowfall $(Z>12 \mathrm{dBZ})$.

[31] These findings have important consequences in the planning of future space missions focused at monitoring snow precipitation in the middle- and high-latitude regions. Recently, two missions have been proposed with this specific aim: SnowSat to the Canadian Space Agency and the Polar Precipitation Missions [Joe et al., 2010] as part of the European Space Agency (ESA) Earth Explore program. In both cases the proposed payload consisted of a dual-frequency $\left(\mathrm{K}_{a}\right.$ and $\left.\mathrm{W}\right)$ band radar, based on the idea that differential reflectivities can be used to size snow particles and to partly mitigate the microphysical deadlock. It is known however that, at these frequencies, Mie effects come into play at relatively large size [Kneifel et al., 2011]; therefore, the dualwavelength radar approach can be effective only on the high snow-rate tail part of the snow distribution (roughly for $Z_{94}$ above $5 \mathrm{dBZ}$, see shaded area in Figure 8). The findings of this paper support the idea of using a lidar system for characterizing the light snow component $\left(Z_{94 \mathrm{GHz}}<5 \mathrm{dBZ}\right)$, which, in our data set, accounts for approximately $45 \%$ of the snow-precipitation amounts and for $80 \%$ of the snow occurrences.

[32] Snow products derived from CloudSat CPR should make full use of the additional information coming from CALIOP. Similar considerations apply for the upcoming EarthCARE mission but also to ground-based remote systems, which are increasingly making use of combined radar and lidar observations. The approach proposed by Delanoë and Hogan [2008] for ice clouds is already used to treat snowbearing clouds in the absence of liquid phase. In such conditions the radar reflectivity modeling should fully account for backscattering cross-sections at $94 \mathrm{GHz}$ of snow particles that significantly deviate from the Debye's solution [Liu, 2008]. On the other hand, the presence of the liquid phase should be used to constrain the a priori for the radaronly retrieval. Ground-based observations (like the ones recently performed during GCPEx within the NASA Global precipitation Mission ground validation program, http://gpm.nsstc.nasa.gov/gcpex/) should help in that respect, 
e.g., by providing dynamic relationships between reflectivity and snow-rate as a function of snow profile characteristics like the presence of SLW, thickness of the system, temperature of the cloud top. Ground-based/air-borne multi-instrument observations should also aim at assessing the pitfalls of the space-borne radar-lidar technique when quantifying the presence of liquid-phase, in relation both to shallow systems, which are prone to radar clutter contamination, and to deep and multilayer systems, which cannot be penetrated by the lidar.

[33] Acknowledgments. Space-borne data were provided by NASA/ CNES and we thank the ICARE Data and Services Center (http://www. icare-lille1.fr) for providing computing support and access to the data used in this study.

[34] A. Battaglia's publication costs were covered by the NCEO EO Mission Support.

\section{References}

Battaglia, A., T. Augustynek, S. Tanelli, and P. Kollias, (2011), Multiple scattering identification in spaceborne W-band radar measurements of deep convective cores, J. Geophys. Res., 116 (D19201), doi:10.1029/ 2011JD016142.

Bauer, P. and A. Mugnai, (2003), Precipitation profile retrieval using temperature-sounding microwave observations, J. Geophys. Res., 108 (D23), 4730-4743.

Brown, P. R. A. and P. N. Francis, (1995), Improved measurements of the ice water content in cirrus using a total-water prob, J. Atmos. Ocean Technol., $12,410-414$.

de Boer, G., H. Morrison, M. D. Shupe, and R. Hildner, (2011), Evidence of liquid dependent ice nucleation in high-latitude stratiform clouds from surface remote sensors, Geophys. Res. Lett., 38(L01803), doi:10.1029/ 2010GL046016.

Delanoë, J. and R. Hogan, (2008), A variational scheme for retrieving ice cloud properties from combined radar, lidar and infrared radiometer, J. Geophys. Res., 113(D07204).

Delanoë, J. and R. Hogan, (2010), Combined CloudSat-CALIPSO-MODIS retrievals of the properties of ice clouds, J. Geophys. Res., 115(D00H29), doi:10.1029/2009JD012346.

Delanoë, J., A. Protat, J. Testud, D. Bouniol, A. J. Heymsfield, A. Bansemer, P. R. A. Brown, and R. M. Forbes, (2005), Statistical properties of the normalized ice particle size distribution, J. Geophys. Res., 110, 10201, doi:10.1029/2004JD005405.

Francis, P. N., P. Hignett, and A. Macke, (1998), The retrieval of cirrus cloud properties from aircraft multi-spectral reflectance measurements during EUCREX'93, Quart. J. Roy. Meteor. Soc., 124, 1273-1291.

Hiley, M. J., M. S. Kulie, and R. Bennartz, (2011), Uncertainty analysis for CloudSat snowfall retrievals, J. Appl. Meteorol. Climatol., 50(2), 399-418, doi: http://dx.doi.org/10.1175/2010JAMC2505.1.

Hogan, R. J. and A. Battaglia, (2008), Fast lidar and radar multiple-scattering models: Part 2: Wide-angle scattering using the time-dependent two-stream approximation, J. Atmos. Sci., 65, 3636-3651, doi: 10.1175/2008JAS2643.1.

Hogan, R. J., M. D. Behera, E. J. O’Connor, and A. J. Illingworth, (2004), Estimate of the global distribution of stratiform supercooled liquid water clouds using the LITE lidar, Geophys. Res. Lett., 31(L05106), doi:10.1029/2003GL018977.

Hogan, R. J., P. N. Francis, H. Flentje, A. J. Illingworth, M. Quante, and J. Pelon, (2003), Characteristics of mixed-phase clouds - 1. Lidar, radar and aircraft observations from CLARE'98, Quart. J. Roy. Meteor. Soc., 129, 2089-2116.

Hogan, R. J., L. Tian, P. R. A. Brown, C. D. Westbrook, A. J. Heymsfield, and J. D. Eastment, (2012), Radar scattering from ice aggregates using the horizontally aligned oblate spheroid approximation, J. Appl. Meteorol. Climatol., 51, 655-671.

Hu, Y.-X., S. Rodier, K. Xu, W. Sun, J. Huang, B. Lin, P. Zhai, and D. Josset, (2010), Occurrence, liquid water content, and fraction of supercooled water clouds from combined CALIOP/IIR/MODIS, J. Geophys. Res., 115 (D00H34), doi:10.1029/2009JD012384.

Hu, Y.-X., et al., (2009), CALIPSO/CALIOP Cloud Phase Discrimination Algorithm, J. Atmos. Ocean Technol., 26, 2293-2309, doi:http://dx.doi. org/10.1175/2009JTECHA1280.1.

Illingworth, A. J., et al., (2007), CLOUDNET: continuous evaluation of cloud profiles in seven operational models using ground-based observations, Bull. Amer. Met. Soc., 88(6), 883-898, doi:10.1175/BAMS-88-6-883.
Joe, P., et al., (2010), The polar precipitation measurement mission. Proc. 6 th European Conference on Radar Meteorology and Hydrology: Satellite radar measurements and hydro-met eorological applications, Sibiu, Romania, 6-10 September, 2010.

Kneifel, S., M. S. Kulie, and R. Bennartz, (2011), A triple-frequency approach to retrieve microphysical snowfall parameters, J. Geophys. Res., 116(D11203), doi:10.1029/2010JD015430.

Kneifel, S., U. Löhnert, A. Battaglia, S. Crewell, and D. Siebler, (2010), Snow scattering signals in ground-based passive microwave radiometer measurements, J. Geophys. Res., 115(D16214), doi:10.1029/2010JD013856.

Kongoli, C., P. Pellegrino, R. R. Ferraro, N. C. Grody, and H. Meng, (2003), A new snowfall detection algorithm over land using measurements from the Advanced Microwave Sounding Unit (AMSU), Geophys. Res. Lett., 30(14), 1756, doi:10.1029/2003GL017177.

Kulie, M. S. and R. Bennartz, (2009), Utilizing spaceborne radars to retrieve dry snowfall, J. Appl. Meteorol. Climatol., 48(12), 2564-2580, doi: http:// dx.doi.org/10.1175/2009JAMC2193.1.

Kulie, M. S., R. Bennartz, T. J. Greenwald, Y. Chen, and F. Weng, (2010), Uncertainties in microwave properties of frozen precipitation: Implications for remote sensing and data assimilation, J. Atmos. Sci., 67, 34713487, doi: http://dx.doi.org/10.1175/2010JAS3520.1.

Liu, G., (2008a), A database of microwave single-scattering properties for nonspherical ice particles, Bull. Amer. Met. Soc., 89, 1563-1570.

Liu, G., (2008b), Deriving snow cloud characteristics from CloudSat observations, J. Geophys. Res., 113(D00A09), doi:10.1029/2007JD00976.

Löhnert, U., S. Kneifel, A. Battaglia, M. Hagen, L. Hirsch, and S. Crewell, (2011), A Multisensor Approach Toward a Better Understanding of Snowfall Microphysics: The TOSCA Project, Bull. Amer. Met. Soc., 92, 613628, doi: http://dx.doi.org/10.1175/2010BAMS2909.1.

Mace, G. G., Q. Zhang, M. Vaughan, R. Marchand, G. Stephens, C. Trepte, and D. Winker, (2009), A description of hydrometeor layer occurrence statistics derived from the first year of merged CloudSat and CALIPSO data, J. Geophys. Res., 114(D00A26), doi:10.1029/2007JD009755.

Matrosov, S., M. Shupe, and I. Djalalova, (2008), Snowfall Retrievals Using Millimeter-Wavelength Cloud Radars. J. Appl. Meteorol. Climatol., 47(3), 769-777, doi: http://dx.doi.org/10.1175/2007JAMC1768.1.

Matrosov, S. Y. and A. Battaglia, (2009), Influence of multiple scattering on CloudSat measurements in snow: a model study, Geophys. Res. Lett., 36 (L12806), doi:10.1029/2009GL038704.

Mugnai, A., et al., (2005), Measuring Precipitation from space: EURAINSAT and the future, chap. Snowfall measurements by the proposed European GPM Mission. Kluwer academic ed., V. Levizzani and P. Bauer and F. J. Turk.

Peterson, B. J., R. M. Holmes, J. W. McClelland, C. J. Vörösmarty, R. B. Lammers, A. I. Shiklomanov, I. A. Shiklomanov, and S. Rahmstorf, (2002), Increasing river discharge to the arctic ocean, Science, 298, 2171-2173, doi:10.1126/science. 1077445 .

Petty, G. W. and W. Huang, (2010), Microwave backscatter and extinction by soft ice spheres and complex snow aggregates, J. Atmos. Sci., 67(3), 769-787, doi: http://dx.doi.org/10.1175/2009JAS3146.1.

Pounder, N. L., R. J. Hogan, T. Varnai, A. Battaglia, and R. F. Cahalan, (2012), A variational method to retrieve the extinction profile in liquid clouds using multiple field-of-view lidar, J. Appl. Meteorol. Climatol., 51,350-365, doi: http://dx.doi.org/10.1175/JAMC-D-10-05007.1.

Pruppacher, H. R. and J. D. Klett, (1997), Microphysics of Clouds and Precipitation. Kluver Academic, Dordrecht.

Rasmussen, R., et al., (2012), The NOAA/FAA/NCAR Winter Precipitation Test Bed: How Well Are We Measuring Snow?, Bull. Amer. Met. Soc., early online release,doi: http://dx.doi.org/10.1175/BAMS-D-11-00052.1.

Rauber, R. M. and A. Tokay, (1991), An explanation for the existence of supercooled water at the top of cold clouds, J. Atmos. Sci., 48(8), 1005-1023, doi: http://dx.doi.org/10.1175/1520-0469(1991)048.

Rawlins, M. A., C. J. Willmott, A. Shiklomanov, E. Linder, S. Frolking, R. B. Lammers, and C. J. Vörösmarty, (2006), Evaluation of trends in derived snowfall and rainfall across eurasia and linkages with discharge to the arctic ocean. Geophys. Res. Lett., 33 (L07403), doi:10.1029/2005GL025231.

Sassen, K. and Z. Wang, (2008), Classifying clouds around the globe with the CloudSat radar: 1-year of results, Geophys. Res. Lett., 35(L04805), doi:10.1029/2007GL032591.

Shupe, M. D., et al., (2008), A focus on mixed-phase clouds, Bull. Amer. Met. Soc., 89(10), 1549-1562, doi: http://dx.doi.org/10.1175/2008BAMS2378.1.

Skofronick-Jackson, G. and B. T. Johnson, (2011), Surface and atmospheric contributions to passive microwave brightness temperatures for falling snow events, J. Geophys. Res., 116(D02213), doi:10.1029/2010JD014438.

Skofronick-Jackson, G., M.-J. Kim, J. A. Weinman, and D.-E. Chang, (2004), A physical model to determine snowfall over land by microwave radiometry, IEEE Trans. Geosci Remote Sens., 42, 1047-1058.

Stephens, G. L., et al., (2008), CloudSat mission: Performance and early science after the first year of operation, J. Geophys. Res., 113, D00A18, doi: 10.1029/2008JD009982. 


\section{BATTAGLIA AND DELANOË: CLOUDSAT-CALIPSO SNOW OBSERVATIONS}

Surussavadee, C. and D. H. Staelin, (2009), Satellite Retrievals of Arctic and Equatorial Rain and Snowfall Rates using Millimeter Wavelengths, IEEE Trans. Geosci. Remote Sens., 47(11), 3697-3707.

Tanelli, S., S. Durden, E. Im, K. Pak, D. Reinke, P. Partain, J. Haynes, and R. Marchand, (2008), Cloudsat's cloud profiling radar after 2 years in orbit: Performance, calibration, and processing, IEEE Trans. Geosci. Remote Sens., 46(11), 3560-3573.

Waliser, D., J.-L. F. Li, T. S. L'Ecuyer, and W.-T. Chen, (2011), The impact of precipitating ice and snow on the radiation balance in global climate models, Geophys. Res. Lett., 38(L06802), doi:10.1029/2010GL046478.

Wang, Y., G. Liu, and E.-K. Seo, (2012), Liquid water in snowing clouds: Implication to satellite remote sensing of snowfall, Atmos. Res., under revision.

Wang, Z. and K. Sassen, (2001), Cloud Type and Macrophysical Property Retrieval Using Multiple Remote Sensors, J. Appl. Meteorol., 40(10), 1665-1682, doi:http://dx.doi.org/10.1175/1520-0450(2001)04 < 1665: CTAMPR2.0.CO;2.
Wang, Z., K. Sassen, D. N. Whiteman, and B. B. Demoz, (2004), Studying Altocumulus with Ice Virga Using Ground-Based Active and Passive Remote Sensors. J. Appl. Meteorol., 43(3), 449-460.

Westbrook, C. D. and A. J. Illingworth, (2011), Evidence that ice forms primarily in supercooled liquid clouds at temperatures $>-27^{\circ} \mathrm{C}$, Geophys. Res. Lett., 38 (L14808), doi:10.1029/2011GL048021.

Westbrook, C. D., A. J. Illingworth, E. J. A. J., O'Connor, and R. J. Hogan, (2010), Doppler lidar measurements of oriented planar ice crystals falling from supercooled and glaciated layer clouds, Quart. J. Roy. Meteor. Soc., 136(646), 260-276, doi:10.1002/qj.528.

Winker, D. M., W. H. Hunt, and M. J. McGill, (2007), Initial performance assessment of CALIOP, Geophys. Res. Lett., 34(L19803), doi:10.1029/ 2007 GL030135.

Zhang, D., Z. Wang, and D. Liu, (2010), A global view of midlevel liquidlayer topped stratiform cloud distribution and phase partition from CALIPSO and CloudSat measurements, J. Geophys. Res., 115(D00H13), doi:10.1029/2009JD012143. 